\title{
Contribution of Murine Double Minute 2 Genotypes to Colorectal Cancer Risk in Taiwan
}

\author{
TE-CHENG YUEH ${ }^{1,2,3,4^{*}}$, YI-WEN HUNG ${ }^{5,6^{*}}$, TZU-CHING SHIH $^{7 *}$, CHENG-NAN WU $^{8}$, \\ SHOU-CHENG WANG ${ }^{3,4}$, YI-LIANG LAI ${ }^{3,4}$, SHIH-WEI HSU ${ }^{3,4}$, MING-HSIEN WU ${ }^{3,4}$, CHUN-KAI FU FU, $^{3,4}$, \\ YUN-CHI WANG ${ }^{2}$, TAO-WEI KE ${ }^{2}$, WEN-SHIN CHANG ${ }^{2}$, CHIA-WEN TSAI ${ }^{2,8}$ and DA-TIAN BAU ${ }^{1,2,9}$ \\ ${ }^{1}$ Graduate Institute of Biomedical Sciences, and ${ }^{7}$ Department of Biomedical Imaging and Radiological Science, \\ China Medical University, Taichung, Taiwan, R.O.C.; \\ ${ }^{2}$ Terry Fox Cancer Research Laboratory, Translational Medicine Research Center, \\ China Medical University Hospital, Taichung, Taiwan, R.O.C.; \\ ${ }^{3}$ Taichung Armed Forces General Hospital, Taichung, Taiwan, R.O.C.; \\ ${ }^{4}$ National Defense Medical Center, Taipei, Taiwan, R.O.C.; \\ ${ }^{5}$ Department of Medicine Research, Taichung Veterans General Hospital, Taichung, Taiwan, R.O.C.; \\ ${ }^{6}$ Animal Radiation Therapy Research Center, and \\ ${ }^{8}$ Department of Medical Laboratory Science and Biotechnology, \\ Central Taiwan University of Science and Technology, Taichung, Taiwan, R.O.C.; \\ ${ }^{9}$ Department of Bioinformatics and Medical Engineering, Asia University, Taichung, Taiwan, R.O.C.
}

\begin{abstract}
Background/Aim: The genomic role of human mouse double minute 2 (MDM2) in colorectal cancer (CRC) is unclear, therefore, our study aimed to evaluate the contribution of MDM2 genotype to the risk of CRC in Taiwan. Materials and Methods: In this case-control study, MDM2 SNP309 $T$ to $G$ (rs2279744) genotypes were determined and their association with CRC risk were investigated among 362 patients with CRC and 362 age- and gender-matched healthy controls in central Taiwan. In addition, the interaction of MDM2 SNP309 genotypes with personal behaviors and clinicopathological features were also examined. Results: The percentage of variant $G G$ for the MDM2 SNP309 genotype was 30.9\% in the CRC group and $24.0 \%$ in the control group, respectively (odds ratio $(O R)=1.78,95 \%$ confidence interval $(C I)=1.25-2.86$,
\end{abstract}

This article is freely accessible online.

*These Authors contributed equally to this study.

Correspondence to: Da-Tian Bau, Chia-Wen Tsai and Wen-Shin Chang, Terry Fox Cancer Research Laboratory, Translational Medicine Research Center, China Medical University Hospital, 2 Yuh-Der Road, Taichung, 404 Taiwan, R.O.C. Tel: +886 422053366 (Ext. 5805), e-mail: datian@mail.cmuh.org.tw; artbau2@gmail.com

Key Words: Colorectal cancer, genotype, MDM2, polymorphism, Taiwan, case-control study. $p=0.0057)$. The allelic frequency distribution analysis showed that the variant $G$ allele of MDM2 SNP309 conferred a significantly increased susceptibility to CRC compared with the wild-type $T$ allele $(O R=1.32,95 \%$ $C I=1.14-1.69, \quad p=0.0062)$. As for the gene-lifestyle interaction, there was an obvious joint effect of MDM2 SNP309 GG genotype on the risk of CRC among eversmokers and non-alcohol drinkers, but not non-smoker or alcohol drinker subgroups. No statistically significant correlation was observed between MDM2 SNP309 genotypic distributions and age, gender, tumor size, location or metastasis status. Conclusion: The genotypes of MDM2 SNP309 may allow forr early detection of and predictor for CRC risk, especially among smokers and non-alcohol drinkers, but not for prognosis. The combined effects of MDM2 SNP309 and other genes (such as matrix metalloproteinases) on CRC susceptibility and prognosis, should also be taken into consideration in the era of precision medicine.

Worldwide, colorectal cancer (CRC) is the third most common cancer and the fourth most common cause of death from cancer (1), and its incidence and mortality rates vary markedly across the globe with regional differences that can sometimes be 10 fold (2, 3). Genetic epidemiology and twin studies [cited in (4)] demonstrated that upwards of $35 \%$ of CRC cases may be due to inherited factors, which indicates the importance of inherited genetic susceptibility in carcinogenesis. In addition to genetic 
background, the mechanisms underlying the development of CRC are complex and lifestyle or environmental factors may also play an important role in the occurrence and progression of CRC (5). In Taiwan, the incidence and mortality of CRC has occupied the first and third places among the common types of cancer for many years and its high incidence has been proposed to be closely associated with dietary changes to Western food style and decrease in the consumption of dietary fiber or grainderived foods. From the epidemiological viewpoint, studies have attributed more than $85 \%$ of CRC etiology to lifestyle/environmental risk factors, particularly meat consumption, cigarette smoking, and exposure to carcinogenic aromatic amines, such as arylamines and heterocyclic amines $(6,7)$. Statistically, $15-20 \%$ of CRC cases have strong familial cancer history that have led molecular epidemiologists to be interested in additional genomic susceptibility factors (8-10). In Taiwan, although specific biomarkers for early detection of CRC have been examined during recent years (11-16), useful genomic markers are still in urgent need and the mechanisms underlying them are largely unknown.

A well-known functional polymorphism of human mouse double minute 2 (MDM2) (SNP309, rs 2279744) is a novel $\mathrm{T}$ to $\mathrm{G}$ substitution located at the 309th nucleotide in the first intron, showing a genomic determiner for binding affinity of its coding protein with the transcription factor Sp1 (17). Therefore, it was rationally hypothesized that the genomic variant may have an impact on the expression level of MDM2 and affect an individual's susceptibility to carcinogenesis. Mounting studies have investigated the association of MDM2 SNP309 genotypes with various tumor types, but their results are controversial and inconclusive (18-20). Some studies have reported a direct connection between MDM2 SNP309 and CRC risk (21-23); however, others have shown the opposite $(24,25)$.

In 2012, Zhang and colleagues reported that there was no significant association between MDM2 SNP309 genotype and CRC, instead, a combined effect of TP53 Arg72Pro and MDM2 SNP309 variant genotype conferred an increased $\mathrm{CRC}$ risk in a Chinese population (26). Considering that the meta-analysis conclusion mentioning the contribution of $M D M 2$ genotype to $\mathrm{CRC}$ risk and evaluating the differences between Asia and Western countries were only based on two investigations in China with limited sample sizes $(26,27)$, more studies are urgently needed to validate these findings. Therefore, in the current case-control study, we aimed to genotype MDM2 SNP309 and evaluate its association with $\mathrm{CRC}$ risk in a Taiwanese population.

\section{Materials and Methods}

Investigated population. The target investigated population consisted of 724 individuals, 362 patients with CRC and 362 controls. The patients diagnosed with CRC were recruited at the outpatient clinics of general surgery during the period of 2002 and 2008 at the China Medical University Hospital in central Taiwan by surgical teams under the supervision of LB Jeng and MD Yang. The clinical characteristics of patients, including histological details, were all graded and defined by expert surgeons $(12-16,28)$. All 724 participants completed a selfadministered questionnaire and provided a 5-ml sample of peripheral blood for genotyping examination. Matched for age, gender and some habits, 362 non-cancer healthy volunteers were selected as controls after initial random sampling from the Health Examination Cohort of the Hospital with the help of colleagues at the Department of Family Medicine. The exclusion criteria of the controls included previous malignancy, metastasized cancer from other or unknown origin and any familial or genetic diseases. This study was approved by the Institutional Review Board of the China Medical University Hospital (IRB project identification coding number: DMR99-IRB-108) and written informed consent was obtained from all the participants with the help of Tissue Bank of China Medical University Hospital. The selective demographic information for the 724 participants in this study is summarized in Table I.

Genotyping conditions. Genomic DNA was extracted from peripheral blood leukocytes with a QIAamp Blood Mini Kit (Blossom, Taipei, Taiwan, ROC), stored long-term at $-80^{\circ} \mathrm{C}$, then diluted and aliquoted for genotyping as a working stock at $-20^{\circ} \mathrm{C}$ as per routine practice $(12$, 13). The $M D M 2$ genotyping methodology regarding the designing of the primer pairs and the selection of restriction enzyme were modified from previously published articles $(24,29)$. In brief, the polymerase chain reaction (PCR) cycling conditions were: one cycle at $94^{\circ} \mathrm{C}$ for 5 min; 35 cycles of $94^{\circ} \mathrm{C}$ for $30 \mathrm{~s}, 59^{\circ} \mathrm{C}$ for $30 \mathrm{~s}$ and $72^{\circ} \mathrm{C}$ for $30 \mathrm{~s}$, and a final extension at $72^{\circ} \mathrm{C}$ for $10 \mathrm{~min}$. The genotyping PCR for $M D M 2$ SNP309 was conducted using 5'-GTTTTGTTGGACTGGGGCTA-3' and 5'-CTGCGATCATCCGGACCT-3' as the forward and reverse primer pairs, respectively. After amplification, the PCR products were subject to enzyme digestion by MspA II restriction endonuclease (New England Biolabs, Beverly, MA, USA) according to the manufacturer's instructions and separation using 3\% agarose gel electrophoresis. All the genotypic processing was repeated by two expert researchers independently and blindly, and their results were $100 \%$ concordant. In addition, the success rate of PCR-restrictive fragment length polymorphism (RFLP) was $100 \%$, and the genotypes of $5 \%$ of the participants in both the control and patient groups were analyzed by PCR direct sequencing (Genomics BioSci \& Tech Co. The concordance between direct sequencing and PCR-RFLP methods was $100 \%$.

Statistical analyses. Student's $t$-test was applied for the comparison of continuous variables such as age between the CRC case and control groups. Pearson's Chi-square was applied to compare the distribution of the MDM2 genotypes among the subgroups. The associations between MDM2 genotypes and CRC risk were estimated by computing odds ratios (ORs) and their $95 \%$ confidence intervals (CIs) from logistic regression analysis. Statistically, any difference between the two groups at $p<0.05$ was taken as significant.

\section{Results}

The frequency distributions of selected demographic characters, including age and gender for the 362 patients with CRC and 362 non-cancer healthy controls, are summarized and compared in Table I. In addition, tumor size, location, and lymph node metastasis status are also 
Table I. Summary of selected data of the 362 patients with colorectal cancer and 362 matched non-cancer healthy controls.

\begin{tabular}{lccc}
\hline $\begin{array}{c}\text { Characteristic } \\
\text { Controls }(\mathrm{n}=362) \\
\mathrm{n}(\%)\end{array}$ & $\begin{array}{c}\text { Cases }(\mathrm{n}=362) \\
\mathrm{n}(\%)\end{array}$ & $p$-Value $^{\mathrm{a}}$ \\
\hline $\begin{array}{l}\text { Age (years) } \\
\leq 60\end{array}$ & $93(25.7 \%)$ & $95(26.2 \%)$ & 0.8654 \\
$>60$ & $269(74.3 \%)$ & $267(73.8 \%)$ & \\
Gender & & & \\
$\quad$ Male & $209(57.7 \%)$ & $203(56.1 \%)$ & 0.6525 \\
$\quad$ Female & $153(42.3 \%)$ & $159(43.9 \%)$ & \\
Tumor size (cm) & & & \\
$\quad<5$ & & $195(53.9 \%)$ & \\
$\geq 5$ & & $167(46.1 \%)$ & \\
Location & & $257(71.0 \%)$ & \\
$\quad$ Colon & & $105(29.0 \%)$ & \\
$\quad$ Rectum & & $210(58.0 \%)$ & \\
Lymph node metastasis & & $152(42.0 \%)$ & \\
$\quad$ Negative & &
\end{tabular}

SD, Standard deviation; abased on Chi-square test without Yates' correction.

reported in Table I. Since we applied frequency matching strategies focusing on age and gender to recruit the 362 noncancer healthy individuals as controls, the data showed that there was no difference in respect of the distributions of age and gender between the two groups ( $p=0.8654$ and 0.6525 , respectively) (Table I).

The distributions of the MDM2 SNP309 genotypes among the 362 non-cancer healthy controls and the 362 patients with CRC are presented and analyzed in Table II. The genotypes of MDM2 SNP309 were differently distributed between the case and control groups ( $p$ for trend=0.0215) (Table II). In detail, the MDM2 SNP309 homozygous GG genotype was associated with increased CRC risk compared with the wild-type TT genotype (adjusted $\mathrm{OR}=1.78,95 \% \quad \mathrm{CI}=1.25-2.86, \quad p=0.0057$ ). However, the heterozygous TG genotype was not associated with altered CRC risk, compared to the wild-type TT genotype (adjusted $\mathrm{OR}=1.34,95 \% \mathrm{CI}=0.96-2.03, p=0.0670$ ). In the dominant model, there was a significant association between $\mathrm{G}$ allele carriers of MDM2 SNP309 and CRC risk compared with TT wild-type genotype (adjusted $\mathrm{OR}=1.53$, $95 \% \mathrm{CI}=1.12-2.28, p=0.0158)$.

In order to confirm the results in Table II, analysis of allelic frequency distributions for MDM2 SNP309 was also conducted and the results are presented in Table III. Supporting the findings that genotype of MDM2 SNP309 was associated with $\mathrm{CRC}$ risk, the frequency of variant allele $\mathrm{G}$ was $56.2 \%$ in the case group, significantly higher than that of $49.0 \%$ in the control group (adjusted $\mathrm{OR}=1.32$, $95 \% \mathrm{CI}=1.14-1.69, p=0.0062$ ) (Table III).
Table II. Distributions of human mouse double minute 2 (MDM2) SNP309 genotypic frequencies among the patients with colorectal cancer and healthy controls.

\begin{tabular}{lcrcc}
\hline Genotype & $\begin{array}{c}\text { Cases, } \\
\mathrm{n}(\%)\end{array}$ & $\begin{array}{c}\text { Controls, } \\
\mathrm{n}(\%)\end{array}$ & $\begin{array}{c}\text { Adjusted OR } \\
(95 \% \mathrm{CI})^{\mathrm{a}}\end{array}$ & $p$-Value ${ }^{\mathrm{b}}$ \\
\hline TT & $67(18.5)$ & $94(26.0)$ & 1.00 (Reference) & \\
TG & $183(50.6)$ & $181(50.0)$ & $1.34(0.96-2.03)$ & 0.0670 \\
GG & $112(30.9)$ & $87(24.0)$ & $\mathbf{1 . 7 8 ( 1 . 2 5 - 2 . 8 6 )}$ & $\mathbf{0 . 0 0 5 7}$ \\
TG+GG & $295(81.5)$ & $268(74.0)$ & $\mathbf{1 . 5 3 ( 1 . 1 2 - 2 . 2 8 )}$ & $\mathbf{0 . 0 1 5 8}$ \\
$p_{\text {trend }}$ & & & & $\mathbf{0 . 0 2 1 5}$ \\
\hline
\end{tabular}

OR, Odds ratio; CI, confidence interval; aData adjusted for confounding factors: age, gender, smoking, alcohol and betel quid consumption; bBased on Chi-square test without Yates' correction. Significant $p$ values $(p<0.05)$ are shown in bold.

Table III. Allelic frequencies for human mouse double minute 2 (MDM2) SNP309 polymorphisms among the patients with colorectal cancer and healthy controls.

\begin{tabular}{lcccc}
\hline Allele & $\begin{array}{c}\text { Cases, } \\
\mathrm{n}(\%) \\
(\mathrm{n}=724)\end{array}$ & $\begin{array}{c}\text { Controls, } \\
\mathrm{n}(\%) \\
(\mathrm{n}=724)\end{array}$ & $\begin{array}{c}\text { Adjusted OR } \\
(95 \% \mathrm{CI})^{\mathrm{a}}\end{array}$ & $p$-Value $^{\mathrm{b}}$ \\
\hline $\mathrm{T}$ & $317(43.8)$ & $369(51.0)$ & 1.00 (Reference) & \\
$\mathrm{G}$ & $407(56.2)$ & $355(49.0)$ & $\mathbf{1 . 3 2 ( 1 . 1 4 - 1 . 6 9 )}$ & $\mathbf{0 . 0 0 6 2}$ \\
\hline
\end{tabular}

OR, Odds ratio; CI, confidence interval. aData adjusted for confounding factors: age, gender, smoking, alcohol and betel quid consumption. bBased on Chi-square test without Yates' correction. Significant $p$ values $(p<0.05)$ are shown in bold.

Since smoking and alcohol drinking habits are well-known risk factors for CRC in Taiwan, we further investigated the interactions between the genotype of MDM2 SNP309 and personal cigarette smoking and alcohol drinking behaviors, and the results presented in Tables IV and V. Firstly, among smokers, those with homozygous GG genotype at MDM2 SNP309 were at 3.20-fold odds of having CRC $(95 \%$ $\mathrm{CI}=1.35-7.58, p=0.0071)$ conferring a risky effect, while this was not the case for the heterozygous TG genotype $(95 \%$ $\mathrm{CI}=0.98-4.84, p=0.0544)$. After adjusting for age, gender and alcohol drinking status, statistical significance still existed at a similar level for GG but not TG genotype (Table IV, right panel). On the other hand, a non-significant effect was found among the non-smokers (Table IV, left panel). Secondly, among alcohol drinkers, those with AG and GG genotypes at MDM2 SNP309 were at non-significantly increased risk of having CRC (95\%CI=0.53-5.13 and 0.96-10.49, $p=0.3876$ and 0.0549 , respectively), while there was a significantly increased risk for those with GG genotype among non- 
Table IV. Odds ratios for association of human mouse double minute 2 (MDM2) SNP309 genotype with colorectal cancer after stratification by smoking status.

\begin{tabular}{|c|c|c|c|c|c|c|c|c|c|c|}
\hline \multirow[t]{2}{*}{ Genotype } & \multicolumn{2}{|c|}{ Non-smokers, $\mathrm{n}$} & \multirow[t]{2}{*}{ OR $(95 \% \mathrm{CI})^{\mathrm{a}}$} & \multirow[t]{2}{*}{$\mathrm{aOR}(95 \% \mathrm{CI})^{\mathrm{b}}$} & \multirow[t]{2}{*}{$p$-Value } & \multicolumn{2}{|c|}{ Smokers, $\mathrm{n}$} & \multirow[t]{2}{*}{ OR $(95 \% \mathrm{CI})^{\mathrm{a}}$} & \multirow[t]{2}{*}{$\mathrm{aOR}(95 \% \mathrm{CI})^{\mathrm{b}}$} & \multirow[t]{2}{*}{$p$-Value } \\
\hline & Controls & Cases & & & & Controls & Cases & & & \\
\hline TT & 69 & 54 & 1.00 (ref) & 1.00 (ref) & & 25 & 13 & 1.00 (ref) & 1.00 (ref) & \\
\hline TG & 143 & 140 & $1.25(0.81-1.91)$ & $1.19(0.84-1.78)$ & 0.3020 & 38 & 43 & $2.18(0.98-4.84)$ & $2.21(0.97-4.68)$ & 0.0544 \\
\hline GG & 66 & 77 & $1.49(0.92-2.42)$ & $1.34(0.95-2.36)$ & 0.1058 & 21 & 35 & $3.20(1.35-7.58)$ & $3.48(1.53-6.89)$ & 0.0071 \\
\hline Total & 278 & 271 & & & & 84 & 91 & & & \\
\hline$p_{\text {trend }}$ & & & & & 0.2700 & & & & & 0.0256 \\
\hline
\end{tabular}

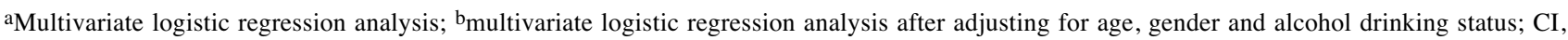
confidence interval; aOR, adjusted odds ratio. Significant $p$-values $(p<0.05)$ are shown in bold.

Table V. Odds ratios for human mouse double minute 2 (MDM2) SNP309 genotype and colorectal cancer after stratification by alcohol drinking status.

\begin{tabular}{|c|c|c|c|c|c|c|c|c|c|c|}
\hline \multirow[t]{2}{*}{ Genotype } & \multicolumn{2}{|c|}{ Non-drinkers, $\mathrm{n}$} & \multirow[t]{2}{*}{ OR $(95 \% \mathrm{CI})^{\mathrm{a}}$} & \multirow[t]{2}{*}{$\mathrm{aOR}(95 \% \mathrm{CI})^{\mathrm{b}}$} & \multirow[t]{2}{*}{$p$-Value } & \multicolumn{2}{|c|}{ Drinkers, $\mathrm{n}$} & \multirow[t]{2}{*}{ OR $(95 \% \mathrm{CI})^{\mathrm{a}}$} & \multirow[t]{2}{*}{$\mathrm{aOR}(95 \% \mathrm{CI})^{\mathrm{b}}$} & \multirow[t]{2}{*}{$p$-Value } \\
\hline & Controls & Cases & & & & Controls & Cases & & & \\
\hline $\mathrm{TT}$ & 81 & 61 & 1.00 (ref) & 1.00 (ref) & & 13 & 6 & 1.00 (ref) & 1.00 (ref) & \\
\hline TG & 156 & 164 & $1.40(0.94-2.08)$ & $1.35(0.95-1.89)$ & 0.0999 & 25 & 19 & $1.65(0.53-5.13)$ & $1.24(0.47-3.21)$ & 0.3876 \\
\hline GG & 74 & 93 & $1.67(1.06-2.62)$ & $1.79(1.24-2.53)$ & 0.0257 & 13 & 19 & $3.17(0.96-10.49)$ & $2.86(0.88-7.45)$ & 0.0549 \\
\hline Total & 311 & 318 & & & & 51 & 44 & & & \\
\hline$p_{\text {trend }}$ & & & & & 0.0780 & & & & & 0.1334 \\
\hline
\end{tabular}

${ }^{a}$ Multivariate logistic regression analysis; ${ }^{\mathrm{b}}$ multivariate logistic regression analysis after adjusting for age, gender and smoking status; CI, confidence interval; aOR, adjusted odds ratio. Significant $p$-values $(p<0.05)$ are shown in bold.

drinkers $(95 \% \mathrm{CI}=1.06-2.62, p=0.0257)$ (Table V). After adjusting for age, gender and smoking status, the trends were still the same for each sub-group (Table V).

The correlations between genotypes of MDM2 SNP309 and clinicopathological features of 362 patients with CRC were further stratified and analyzed in Table VI. No statistically significant correlation was observed between MDM2 SNP309 genotypic distributions and age, gender, tumor size, location or metastasis status (all $p>0.05$ ) (Table VI).

\section{Discussion}

MDM2 protein was originally identified as an oncoprotein which binds to p53 and inhibits p53-mediated transactivation and MDM2 is reported to be overexpressed in many tumor sites such as sarcomas, osteosarcomas and esophageal sarcomas $(30,31)$. As originally identified, MDM2 can directly bind to p53 and down-regulate its function as a tumor suppressor. Therefore, the oncogenic properties of MDM2 are thought to be p53-dependent. However, some scientists have reported that MDM2 may form complexes with other tumor-suppressor proteins independently of p53 in p53-deficient cells, which indicated that the oncogenic function of MDM2 was p53-independent (32, 33). Most importantly, although MDM2 SNP309 is located at the p53response intronic promoter region, the p53-independent overexpression of MDM2 was still observed (34). In a few reports, it was found that MDM2 amplification might be regulated at the post-transcriptional level $(35,36)$. All the aforementioned findings indicate that complex mechanisms underlie the regulation of MDM2 gene during tumorigenesis and which are largely unknown. Considering that MDM2 SNP309 may closely regulate the expression level of MDM2 protein, it is of great value to evaluate its association with cancer risk, such as CRC risk in Taiwan.

In the present study, we firstly found that GG genotype at MDM2 SNP309 was associated with increased risk of CRC in this Taiwanese population (Table II). In the literature on genomic studies of CRC, whether MDM2 SNP309 has a direct effect on carcinogenesis is still controversial. Similarly, some reported findings that the TG genotype is associated with increased CRC risk compared with the TT genotype (21-23), whereas other reports have provided negative results with no significant association $(24,25)$. 
Table VI. Correlation between human mouse double minute 2 (MDM2) SNP309 genotype and clinicopathological features of 362 patients with colorectal cancer.

\begin{tabular}{|c|c|c|c|c|c|}
\hline \multirow[t]{2}{*}{ Characteristic } & \multirow[t]{2}{*}{ Cases, $\mathrm{n}$} & \multicolumn{3}{|c|}{ Genotype, n (\%) } & \multirow[t]{2}{*}{$p$-Value $^{\mathrm{a}}$} \\
\hline & & $\mathrm{TT}$ & TG & GG & \\
\hline \multicolumn{6}{|l|}{ Age } \\
\hline$\leq 60$ Years & 95 & $16(16.8)$ & $49(51.6)$ & $30(31.6)$ & 0.8882 \\
\hline$>60$ Years & 267 & $51(19.1)$ & $134(50.2)$ & $82(30.7)$ & \\
\hline \multicolumn{6}{|l|}{ Gender } \\
\hline Male & 203 & $35(17.2)$ & $106(52.2)$ & $62(30.6)$ & 0.7126 \\
\hline Female & 159 & $32(20.1)$ & $77(48.4)$ & $50(31.5)$ & \\
\hline \multicolumn{6}{|l|}{ Tumor size } \\
\hline$<5 \mathrm{~cm}$ & 195 & 33 (16.9) & $95(48.7)$ & $67(34.4)$ & 0.2933 \\
\hline$\geq 5 \mathrm{~cm}$ & 167 & $34(20.4)$ & $88(52.7)$ & 45 (26.9) & \\
\hline \multicolumn{6}{|l|}{ Location } \\
\hline Colon & 257 & $46(17.9)$ & $128(49.8)$ & $83(32.3)$ & 0.6695 \\
\hline Rectum & 105 & $21(20.0)$ & $55(52.4)$ & $29(27.6)$ & \\
\hline \multicolumn{6}{|c|}{ Lymph node metastasis } \\
\hline Negative & 210 & $42(20.0)$ & $105(50.0)$ & $63(30.0)$ & 0.6791 \\
\hline Positive & 152 & $25(16.5)$ & $78(51.3)$ & $49(32.2)$ & \\
\hline
\end{tabular}

aBased on Chi-square test without Yates's correction.

Recently, Zhang and colleagues reported a combined effect of TP53 Arg72Pro and MDM2 SNP309 in a dose-response manner, increasing CRC risk in a population from central China, but still no association between MDM2 SNP309 alone and CRC risk was found (26). In our study population, the MDM2 SNP309 GG carriers, but not those with TG, were found to have an increased CRC risk compared to those carrying TT genotype (Table II). Interestingly, a metaanalysis published in 2012 also found an increased CRC risk among individuals with TG genotype, especially among Asians, when compared to the TT genotype (37). However, no association was found between MDM2 SNP309 and CRC risk among Europeans. Considering the frequencies of the MDM2 SNP309 $\mathrm{G}$ allele among the cases and controls were different by ethnicity (minor allelic frequency: 0.47 in Asians and 0.39 in Europeans), this indicates a possible ethnic difference in genetic background.

Long-term smoking has been reported as a risk factor for CRC (38), thus we are interested in the interaction of MDM2 genotype and smoking on CRC risk. Not among the nonsmokers, but the smokers, we found that GG genotype was associated with an increased risk of CRC in Taiwanese (Table IV). Similarly, Zhang and colleagues also reported that the interaction between TP53 Arg72Pro and MDM2 SNP309 was associated with elevated CRC risk among smokers but not among non-smokers (26). In addition to smoking, alcohol consumption is also associated with CRC risk (39), and thus we were interested in the interaction of MDM2 genotype and alcohol drinking on CRC risk. We found that $\mathrm{t}$ GG genotype was associated with an increased risk of CRC among nonalcohol drinkers but not drinkers in Taiwanese (Table V).

We also examined the correlations between genotypes of MDM2 SNP309 and clinicopathological features of investigated patients with CRC in Taiwan. The influence of MDM2 SNP309 on CRC risk was previously found to be more pronounced among older people, which may reflect the cumulative effects of risk factors, such as prolonged red meat consumption (40); we found no significant association with age. The second factor analyzed was gender, but no significant difference was found (Table VI). In a study of a Japanese population, increased CRC risk found to be associated with MDM2 SNP309 only in men but not in women (22). A significant earlier age of onset was observed to be associated with MDM2 SNP309 for several tumor types (17). In addition, several studies showed the association of MDM2 SNP309 with CRC risk especially in women, but not in men $(24,41)$. The biological explanation for the inconsistence of our finding with others may be that CRC among Taiwanese is very prevalent, no matter in men or women, and has a trend for early onset. Regarding tumor size, location and lymph node metastasis, we did not find any determinant effect of MDM2 SNP309 on CRC in the patients we investigated (Table VI).

From the viewpoint of molecular interaction, MDM2 SNP309 variants might lead to a relatively lower activity of p53, and thereby increase the possibility that some colon cells may be more vulnerable to damage by tobacco carcinogens or alcohol and might escape apoptosis triggered 
by p53. Therefore, smokers carrying MDM2 SNP309 are expected to have a higher risk of CRC, but further validation is still needed.

In conclusion, we provide evidence showing that MDM2 SNP309 was associated with increased CRC risk in a Taiwanese population. Additionally, in the stratified analyses, we found that increased risk was more pronounced among smokers and non-alcohol drinkers. Moreover, earlier age of cancer onset or gender difference among patients carrying MDM2 SNP309 variant genotypes was not found in our study unlike others. We hope to validate the combined effects of $p 53$ and MDM2 on CRC risk in Taiwanese, and further validation of large population-based studies in different ethnicities are urgently encouraged and needed.

\section{Acknowledgements}

The Authors declare no conflict of interest in regard to this study. We appreciate the Tissue-bank of China Medical University Hospital for their excellent technical assistance and all the subjects, doctors, nurses and colleagues. The perfect technology and efforts from Yu-Shih Wang, Huai-Mei Hsu and Hsin-Ting Li are also appreciated. This study was supported mainly by the Taichung Armed Forces General Hospital (107A19) to Dr. Yueh, Taichung Veterans General Hospital (TCVGH-CTUST1077701) to Dr. Hung and $\mathrm{Dr}$. Wu, and partially by research grant from Taiwan Ministry of Health and Welfare Clinical Trial and Research Center of Excellence (MOHW107-TDU-B-212-123004).

\section{References}

1 Jemal A, Bray F, Center MM, Ferlay J, Ward E and Forman D: Global cancer statistics. CA Cancer J Clin 61: 69-90, 2011.

2 Douaiher J, Ravipati A, Grams B, Chowdhury S, Alatise O and Are C: Colorectal cancer-global burden, trends, and geographical variations. J Surg Oncol 115: 619-630, 2017.

3 Arnold M, Sierra MS, Laversanne M, Soerjomataram I, Jemal A and Bray F: Global patterns and trends in colorectal cancer incidence and mortality. Gut 66: 683-691, 2017.

4 Markowitz SD and Bertagnolli MM: Molecular origins of cancer: Molecular basis of colorectal cancer. N Engl J Med 361: 2449-2460, 2009.

5 Lichtenstein P, Holm NV, Verkasalo PK, Iliadou A, Kaprio J, Koskenvuo M, Pukkala E, Skytthe A and Hemminki K: Environmental and heritable factors in the causation of cancer analyses of cohorts of twins from Sweden, Denmark, and Finland. N Engl J Med 343: 78-85, 2000.

6 Nagini S: Carcinoma of the stomach: A review of epidemiology, pathogenesis, molecular genetics and chemoprevention. World $\mathbf{J}$ Gastrointest Oncol 4: 156-169, 2012.

7 Jayasurya R, Sathyan KM, Lakshminarayanan K, Abraham T, Nalinakumari KR, Abraham EK, Nair MK and Kannan S: Phenotypic alterations in $\mathrm{Rb}$ pathway have more prognostic influence than p53 pathway proteins in oral carcinoma. Mod Pathol 18: 1056-1066, 2005.

8 Butterworth AS, Higgins JP and Pharoah P: Relative and absolute risk of colorectal cancer for individuals with a family history: a meta-analysis. Eur J Cancer 42: 216-227, 2006.
9 Houlston RS and Tomlinson IP: Polymorphisms and colorectal tumor risk. Gastroenterology 121: 282-301, 2001.

10 Rasool S, Rasool V, Naqvi T, Ganai BA and Shah BA: Genetic unraveling of colorectal cancer. Tumour Biol 35: 5067-5082, 2014.

11 Lin KM, Yang MD, Tsai CW, Chang WS, Hsiao CL, Jeng LB, Yueh TC, Lee MC and Bau DT: The role of MTHFR genotype in colorectal cancer susceptibility in Taiwan. Anticancer Res 38: 2001-2006, 2018.

12 Yueh TC, Chou AK, Gong CL, Fu CK, Pei JS, Wu MH, Tsai CW, Chang WS, Hsiao CL, Yen ST, Li HT and Bau DT: The contribution of excision repair cross-complementing group 1 genotypes to colorectal cancer susceptibility in Taiwan. Anticancer Res 37: 2307-2313, 2017.

13 Shih LC, Li CH, Sun KT, Chen LY, Hsu CL, Hung YW, Wu CN, Hsia TC, Shen TC, Chang WS, Shih TC, Tsai CW and Bau DT: Association of matrix metalloproteinase-7 genotypes to the risk of oral cancer in Taiwan. Anticancer Res 38: 2087-2092, 2018.

14 Huang CY, Tsai CW, Hsu CM, Chang WS, Shui HA and Bau DT: The significant association of CCND1 genotypes with colorectal cancer in Taiwan. Tumour Biol 36: 6533-6540, 2015.

15 Yang MD, Tsai CW, Chang WS, Tsou YA, Wu CN and Bau DT: Predictive role of XRCC5/XRCC6 genotypes in digestive system cancers. World J Gastrointest Oncol 3: 175-181, 2011.

16 Yang MD, Tsai RY, Liu CS, Chang CH, Wang HC, Tsou YA, Wang CH, Lin CC, Shyue SK and Bau DT: Association of caveolin-1 polymorphisms with colorectal cancer susceptibility in Taiwan. World J Gastrointest Oncol 2: 326-331, 2010.

17 Bond GL, Hu W, Bond EE, Robins H, Lutzker SG, Arva NC, Bargonetti J, Bartel F, Taubert H, Wuerl P, Onel K, Yip L, Hwang SJ, Strong LC, Lozano G and Levine AJ: A single nucleotide polymorphism in the MDM2 promoter attenuates the p53 tumor-suppressor pathway and accelerates tumor formation in humans. Cell 119: 591-602, 2004.

18 Lind H, Zienolddiny S, Ekstrom PO, Skaug V and Haugen A: Association of a functional polymorphism in the promoter of the MDM2 gene with risk of nonsmall cell lung cancer. Int J Cancer 119: 718-721, 2006.

19 Hong Y, Miao X, Zhang X, Ding F, Luo A, Guo Y, Tan W, Liu $\mathrm{Z}$ and Lin D: The role of $P 53$ and MDM2 polymorphisms in the risk of esophageal squamous cell carcinoma. Cancer Res 65: 9582-9587, 2005.

$20 \mathrm{Ma} \mathrm{H}, \mathrm{Hu}$ Z, Zhai X, Wang S, Wang X, Qin J, Jin G, Liu J, Wang X, Wei Q and Shen H: Polymorphisms in the $M D M 2$ promoter and risk of breast cancer: a case-control analysis in a Chinese population. Cancer Lett 240: 261-267, 2006.

21 Alazzouzi H, Suriano G, Guerra A, Plaja A, Espin E, Armengol M, Alhopuro P, Velho S, Shinomura Y, Gonzalez-Aguilera JJ, Yamamoto H, Aaltonen LA, Moreno V, Capella G, Peinado MA, Seruca R, Arango D and Schwartz S Jr.: Tumour selection advantage of non-dominant negative P53 mutations in homozygotic MDM2-SNP309 colorectal cancer cells. J Med Genet 44: 75-80, 2007.

22 Joshi AM, Budhathoki S, Ohnaka K, Mibu R, Tanaka M, Kakeji Y, Maehara Y, Okamura T, Ikejiri K, Futami K, Maekawa T and Yasunami Y: TP53 R72P and MDM2 SNP309 polymorphisms and colorectal cancer risk: The Fukuoka Colorectal Cancer Study. Jpn J Clin Oncol 41: 232-238, 2011. 
23 Chaar I, Arfaoui TA, El Amine el HO, Mahmoud LB, Khiari M, Sammoud S, Lounis A, Amara S, Gharbi L, Hmida AB, Mzabi $\mathrm{S}$ and Bouraoui S: Impact of MDM2 polymorphism: increased risk of developing colorectal cancer and a poor prognosis in the Tunisian population. Eur J Gastroenterol Hepatol 24: 320-327, 2012.

24 Alhopuro P, Ylisaukko-Oja SK, Koskinen WJ, Bono P, Arola J, Jarvinen HJ, Mecklin JP, Atula T, Kontio R, Makitie AA, Suominen S, Leivo I, Vahteristo P, Aaltonen LM and Aaltonen LA: The $M D M 2$ promoter polymorphism SNP309T-->G and the risk of uterine leiomyosarcoma, colorectal cancer, and squamous cell carcinoma of the head and neck. J Med Genet 42: 694-698, 2005.

25 Talseth BA, Meldrum C, Suchy J, Kurzawski G, Lubinski J and Scott RJ: MDM2 SNP309 T $>\mathrm{G}$ alone or in combination with the TP53 R72P polymorphism does not appear to influence disease expression and age of diagnosis of colorectal cancer in HNPCC patients. Int J Cancer 120: 563-565, 2007.

26 Zhang Y, Liu L, Tang Y, Chen C, Wang Q, Xu J, Yang C, Miao $\mathrm{X}$, Wei S, Chen $\mathrm{J}$ and Nie S: Polymorphisms in TP53 and $M D M 2$ contribute to higher risk of colorectal cancer in Chinese population: a hospital-based, case-control study. Mol Biol Rep 39: 9661-9668, 2012.

27 Wang W, Du M, Gu D, Zhu L, Chu H, Tong N, Zhang Z, Xu Z and Wang M: MDM2 SNP309 polymorphism is associated with colorectal cancer risk. Sci Rep 4: 4851, 2014.

28 Bau DT, Yang MD, Tsou YA, Lin SS, Wu CN, Hsieh HH, Wang RF, Tsai CW, Chang WS, Hsieh HM, Sun SS and Tsai RY: Colorectal cancer and genetic polymorphism of DNA doublestrand break repair gene XRCC4 in Taiwan. Anticancer Res 30: 2727-2730, 2010.

29 Menin C, Scaini MC, De Salvo GL, Biscuola M, Quaggio M, Esposito G, Belluco C, Montagna M, Agata S, D'Andrea E, Nitti D, Amadori A and Bertorelle R: Association between MDM2SNP309 and age at colorectal cancer diagnosis according to $p 53$ mutation status. J Natl Cancer Inst 98: 285-288, 2006.

30 Hao XP, Gunther T, Roessner A, Price AB and Talbot IC: Expression of MDM2 and p53 in epithelial neoplasms of the colorectum. Mol Pathol 51: 26-29, 1998.

31 Momand J, Jung D, Wilczynski S and Niland J: The MDM2 gene amplification database. Nucleic Acids Res 26: 3453-3459, 1998.

32 Martin K, Trouche D, Hagemeier C, Sorensen TS, La Thangue NB and Kouzarides T: Stimulation of E2F1/DP1 transcriptional activity by MDM2 oncoprotein. Nature 375: 691-694, 1995.
33 Xiao ZX, Chen J, Levine AJ, Modjtahedi N, Xing J, Sellers WR and Livingston DM: Interaction between the retinoblastoma protein and the oncoprotein MDM2. Nature 375: 694-698, 1995.

34 Ries S, Biederer C, Woods D, Shifman O, Shirasawa S, Sasazuki T, McMahon M, Oren M and McCormick F: Opposing effects of RAS on p53: transcriptional activation of MDM2 and induction of p19ARF. Cell 103: 321-330, 2000.

35 Gudas JM, Nguyen H, Klein RC, Katayose D, Seth P and Cowan KH: Differential expression of multiple MDM2 messenger RNAs and proteins in normal and tumorigenic breast epithelial cells. Clin Cancer Res 1: 71-80, 1995.

36 Maya R, Balass M, Kim ST, Shkedy D, Leal JF, Shifman O, Moas M, Buschmann T, Ronai Z, Shiloh Y, Kastan MB, Katzir E and Oren M: ATM-dependent phosphorylation of MDM2 on serine 395: Role in p53 activation by DNA damage. Genes Dev 15: 1067-1077, 2001.

37 Cao X, Zhang $\mathrm{T}$, Zhao $\mathrm{Z}$ and Zhao T: MDM2 SNP309 polymorphism and colorectal cancer risk: a meta-analysis. DNA Cell Biol 31: 355-359, 2012.

38 Terry P, Ekbom A, Lichtenstein P, Feychting M and Wolk A: Long-term tobacco smoking and colorectal cancer in a prospective cohort study. Int J Cancer 91: 585-587, 2001.

39 Fedirko V, Tramacere I, Bagnardi V, Rota M, Scotti L, Islami F, Negri E, Straif K, Romieu I, La Vecchia C, Boffetta P and Jenab $\mathrm{M}$ : Alcohol drinking and colorectal cancer risk: an overall and dose-response meta-analysis of published studies. Ann Oncol 22: 1958-1972, 2011.

40 zur Hausen H: Red meat consumption and cancer: Reasons to suspect involvement of bovine infectious factors in colorectal cancer. Int J Cancer 130: 2475-2483, 2012.

41 Bond GL, Menin C, Bertorelle R, Alhopuro P, Aaltonen LA and Levine AJ: MDM2 SNP309 accelerates colorectal tumour formation in women. J Med Genet 43: 950-952, 2006.
Received June 6, 2018

Revised June 19, 2018

Accepted June 20, 2018 